\title{
Treatment trends in oral lichen planus and oral lichenoid lesions (Review)
}

\author{
DOINA ROTARU ${ }^{1 *}$, RADU CHISNOIU $^{1 *}$, ALINA MONICA PICOS $^{2}$, \\ ANDREI PICOS $^{3}$ and ANDREA CHISNOIU ${ }^{2 *}$
}

\begin{abstract}
${ }^{1}$ Department of Odontology, Endodontics and Oral Pathology, 'Iuliu Hatieganu' University of Medicine and Pharmacy, 400001 Cluj-Napoca; ${ }^{2}$ Department of Prosthodontics, 'Iuliu Hatieganu' University of Medicine and Pharmacy, 400006 Cluj-Napoca; ${ }^{3}$ Department of Prevention in Dental Medicine,

'Iuliu Hatieganu' University of Medicine and Pharmacy, 400089 Cluj-Napoca, Romania
\end{abstract}

Received July 14, 2020; Accepted August 13, 2020

DOI: $10.3892 /$ etm.2020.9328

\begin{abstract}
Oral lichen planus (OLP) is a chronic inflammatory disease, associated with altered cell-mediated immunological function. It has long-term evolution, repeated exacerbations, sometimes painful and resistant to treatment, even all of these, OLP significantly affects patient's life quality. Not least, OLP is accompanied by an increased risk of malignant transformation. A wide spectrum of therapeutic options is available, but none are curative. In this review, 58 structured studies on the clinical symptomatology and treatment strategy of OLP were analyzed. The literature research was performed according to the criteria of the PRISMA system. This study summarizes current knowledge regarding management of OLP and oral lichenoid lesions, discusses the challenges of choosing an adequate treatment and, in attempt to improve the quality of patient life, trying to describe a therapeutic algorithm that takes into consideration the clinical features of the disease. Current OLP therapy aims at eliminating all mucosal-related lesions, reduce symptomatology and decrease the risk of oral cancer and include corticosteroids, immunomodulatory agents, retinoids, ultraviolet irradiation and/or laser therapy.
\end{abstract}

\section{Contents}

1. Introduction

2 Terminology

3 Materials and methods

4. Conclusions

Correspondence to: Professor Alina Monica Picos, Department of Prosthodontics, 'Iuliu Hatieganu' University of Medicine and Pharmacy, 32 Clinicilor Street, 400006 Cluj-Napoca, Romania E-mail: alinapicos@yahoo.com

*Contributed equally

Key words: oral lichenoid lesions, oral lichen planus, management; treatment; therapeutic algorithm; immunity

\section{Introduction}

Lichen planus (LP) is a dermatological condition that affects the skin and/or mucous membranes, frequently encountered in middle age women, but also in males. The disorder affects all ethnicities; no ethnic group has been identified as being of particular risk (1).

It most commonly affects the oral mucosa and skin; the genital, eye and esophageal mucosa, the nails and scalp may also be involved (2). The frequence in general population has been reported between 0.5 and $2.6 \%$ (3).

\section{Terminology}

The term OLP concerns a idiopathic lesion, which means that a trigger cannot be identified, instead the term oral lichenoid lesion (OLL) was introduced by Finne in 1982 and defines oral lesions that are associated with bone marrow transplantation, drug intake, dental restorative materials, food or flavor allergies and systemic disease (autoimmune liver disease) (4-6).

\section{Materials and methods}

In this review, 58 structured studies on the clinical simtomatology and treatment options of oral lichen planus (OLP) were analyzed. The literature research was performed according to the criteria of the PRISMA system. Electronic databases (PubMed, Scopus, and Web of Science) were scanned starting with the date of inception and ending with December 2019, using various combinations of key words such as: OLP, lichenoid lesions, clinical symptomatology and treatment protocol. Since the obtained data were heterogeneous, no statistical analyses were conducted. Initially, 4105 publications were identified. Supplementary refining criteria were added such as: Study on human subjects, language publication (English, German or French) and full text available. Studies approaching serology, genetics and biomarkers, were excluded from the initial database. Case reports were not taken into consideration. Finally, only 58 studies were included in this review. 
Pathogenesis. LP is a T-cell mediated immune response of unknown origin (7) in which the auto-cytotoxic $\mathrm{CD} 8^{+} \mathrm{T}$ cells trigger apoptosis of the basal cells of the oral epithelium $(8,9)$.

Cell-mediated immune mechanism starts with keratinocytes antigen expression; this process is followed by migration of $\mathrm{T}$ cell lymphocytes, which are activated directly by an antigen binding to major histocompatibility complex (MHC)-1 on keratinocytes or through activated $\mathrm{CD}^{+}$lymphocytes (10).

The activated $\mathrm{CD} 8^{+} \mathrm{T}$ cells in turn kill the basal keratinocytes through tumor necrosis factor (TNF)- $\alpha$, Fas-FasL-mediated or granzyme B-activated apoptosis (11). Non-specific mechanisms further aggravate the T-cell accumulation, BM disruption by mast cell proteases and keratinocyte apoptosis $(12,13)$.

Clinical presentation. OLP presents in a wide range of clinical forms, usually bilateral, or less frequent unilateral, more or less symmetrical, involving the oral mucosa, dorsum and ventral surfaces of the tongue, and/or gingiva (causing inflammation often referred as desquamative gingivitis). Palatal and labial localisation is rarely encountered. Literature describes six types of lesions (14): Reticular, papular, plaque-like-white forms-, atrophic (erythematous), erosive (ulcerated) and bullous-red forms (15). Clinical types of OLP may occur alone or in various combinations (16).

Diagnosis of OLP and OLL is a diagnostic challenge for clinicians. The diagnostic criteria of OLP was introduced by WHO in 1978 (17), and modified by van der Meij and van der Waal in 2003 (18). In 2016, the American Academy of Oral and Maxillofacial Pathology (19) proposed new clinical and histopathologic criteria. Clinical criteria consists of white and red multifocal lesions with symmetric distribution, one or more of the following forms: Reticular/papular, atrophic (erythematous), erosive (ulcerative), plaque, bullous lesions are also localized outside the sites of tobacco placement, close to and in contact with dental restorations. The appearance of lesions does not correlate with the start of a drug, or use of cinnamon-containing products. The histopathologic examination indicates band-like or patchy, mostly lymphocytic infiltrate in the lamina propria limited to the epithelium-lamina propria interface, basal cell liquefactive (hydropic) degeneration, lymphocytic exocytosis, without any epithelial dysplasia, or verrucous epithelial architectural change.

To a clear and precise final diagnosis, a thorough history and clinical features of lesions should be correlated with complex testing-histopathologic examination, DIF, IIF, cutaneous patch testing (20-22). Also, it is important to mention that the diagnostic process of OLP and OLL demands continuous follow-up and if necessary additional biopsies for histopathological evaluation and immunofluorescence tests $(23,24)$.

Management and treatment. A stepwise approach should be adopted. The first step is establishment of diagnosis, based on history, clinical examination, and complex testing-histopathology examination, direct immunofluorescence (DIF), indirect immunofluorescence (IIF), cutaneous patch testing, as stated above.
The second step is to inform the patient of the following: OLP is a chronic disease with expected periods of flare-ups and symptom-free periods; disease activity may present fluctuation in each patient (25); the aims of treatment are elimination of painful symptoms, healing of ulcerative lesions, decreasing the risk or oral cancer, prolongation of symptom free periods and the maintenance of good oral hygiene and dental status (26); no therapy for OLP is completely curative because of its recalcitrant nature and also its idiopathic etiology, several treatments may need to be tried; current therapies have local and systemic adverse effects; lesion recurrence after treatment is reduced (27); maintaining a high standard of oral hygiene as well as dental status, elimination of any cause of mucosal trauma may contribute to control severity of oral lesions (28); maintaining a regular and healthy life, less than $20 \%$ of OLP lesions may regress without treatment (29); avoiding all hot, salty, acidic or spicy food, as well as smoking and alcohol intake, especially in patients with atrophic and erosive lesions; controlling stress may help in treatment (relaxation training); the potentially increased risk of oral cancer, more common in smokers, with erosive and atrophic lesions and an evolution period up to five years and in persons with OLL (30).

Therapeutic attitude depends on associated symptoms and clinical presentation. In asymptomatic, non-ulcerative lesions of OLP no pharmacologic intervention is required and follow-up is indicated.

For symptomatic, non-ulcerative LP a topical anesthetic benzydamine hydrochloride $(0.15 \%)$ is indicated. Tantum, liquid/spray for topical application or oral rinse can also be used. The usual dose for an adult is at least $15 \mathrm{ml}(1$ tablespoon) for mouth rinsing, 3 or 4 times a day, according to the severity of the lesions. This dose should be administered at intervals of more than three hours, and maximum eight doses in a $24-h$ period.

Alternatively, it is recomended for the patient to apply on the painful areas a gel containing $2 \%$ lidocaine. Follow-up is indicated every 6 months.

In cases of symptomatic and/or atrophic or erosive lichen planus treatment plan may vary. Lesions that are dysplastic or present malignant transformation should be treated accordingly.

For lesions that are not dysplastic and do not show malignant transformations, topical steroids should be taken into consideration. These were recommended as first-line treatment in consensus guidelines published in 2005 (31).

According to the severity of the lesions, and personal experience of doctors, available drugs may be prescribed: soluble prednisolone tablets, mouthwash rinsing 3 or 4 times in $24 \mathrm{~h}(5 \mathrm{mg}$ dissolved in $15 \mathrm{ml}$ of water); soluble betamethasone tablets $(500 \mathrm{mg}$ ) dissolved in $10-15 \mathrm{ml}$ of water, used for mouth rinse up to 4 times daily; beclomethasone dipropionate (100 mcg/puff), fluticasone propionate $(50 \mathrm{mcg} /$ puff), metered dose inhalers, used as mouth sprays, applied on the lesions up to 3-4 times daily (32); Clobetasol ointment $(0.05 \%)$ applied to painful affected areas 3-4 times in $24 \mathrm{~h}$; Fluticasone cream $(0.05 \%)$ applied to painful lesions 3-4 times daily (33).

The reduced time of adherence for the topical corticosteroids to the mucosa represents one of their main disadvantages. 
Considering this, topical steroids such as betamethasone valerate, clobetasol, fluocinolone acetonide, fluocinonide and triamcinolone acetonide were included in adhesive paste formulas in order to improve their adhesion to the oral mucosa (e.g. Orabase, ConvaTec, Montreal, Que-gelatin-pectin-sodium carboxymethylcellulose-based). A proprietary product is not available $(34,35)$. The adhesive pastes used for dentures represent another option. Some authors consider that these pastes have excellent bio-adhesive properties and represent an excellent carrier for the active substances used in topical applications (36). With limited indications, cloth strips and custom trays may serve as support for the corticosteroid application (37).

Limited lesions located on the fixed oral mucosa (gingiva and palate) can be treated using ointments, creams and adherent paste; this technique has the advantage in controling the contact time and the extension of the surface exposed to the drugs (38).

Wide spread forms of OLP require as treatment high-potent and superpotent corticosteroid mouthwashes and/or intralesional injections, as follows: aqueous triamcinolone acetonide 1.0 or $0.1 \mathrm{mg} / \mathrm{ml}$ dexamethasone elixir; $(5 \mathrm{ml}$ of the solution in mouthwash for $2 \mathrm{~min}$ after meals and at night) (39); hydrocortisone hemisuccinate in aqueous solution (40); Systemic administration of steroids present more adverse effects than local application. Among side effects: Candidiasis, thinning of the oral mucosa and discomfort on application can be encountered. Adrenal suppression has been reported as a possible side effect of topical formulations of the more potent corticosteroids when used in large amounts for long periods of time or with occlusive dressings. It is very important to use the lowest-potency steroid that proves effective; antifungal preparations (considering that candidiasis is the most frequent adverse effect that occures when topical corticosteroid therapy is used), miconazole gel alone or with chlorhexidine mouthwashes (39).

If there is a lack of response, in the case of some severe and symptomatic, OLP (atrophic/ulcerative), unresponsive to topical measures, and there is no contraindication for systemic steroids, intralesional and submucosal injection of corticosteroid should be considered (41). The recommended injection is $0.2-0.4 \mathrm{ml}$ of a $10 \mathrm{mg} / \mathrm{ml}$ solution of triamcinolone acetonide (kenacort A) one dose/week, 2-3 doses, in association with oral administration of prednisolone (one dose of 15-30 mg prednisolone/day for 2 weeks; the oral administration of prednisolone is progressively decreased to $5 \mathrm{mg}$ per day and stopped in the third week) (42).

The systemic administration of prednisolone is indicated in case of the severest multifocal lesions with large areas of ulceration. The usual adult dose is $40 \mathrm{mg}$ of prednisolone per day for the first 5 days and then the dose is reduced to $10-20 \mathrm{mg}$ of prednisolone daily for the next 7-10 days. This treatment protocol can significantly improve the healing rate of the lesions (29).

Using corticosteroid ointments in topical administration may treat any residual minor lesions. It is not recommended to maintain long-term corticosteroid therapy due to the adverse effects such as: Adrenocortical suppression, hypertension, hyperglycemia, weight gain, mood alteration, insomnia, gastrointestinal irritation, osteoporosis.
Due to its inconsistent evolution, exacerbations of the disease are implacable and the patient should be warned that corticosteroids therapy might be reapplied $(29,30)$.

In cases with contraindications for systemic steroids (breast-feeding, herpetic infections, glaucoma, pregnancy, HIV, tuberculosis, diabetes mellitus or hypertension), other immunosuppressants and immunomodulatory agents are indicated: Calcineurin inhibitors (cyclosporine, tacrolimus, pimecrolimus), mycophenolate mofetil, efalizumab.

When cyclosporine is used it can be topically administered with adhesive bases or as a mouth rinse. This treatment has very high costs and it should be reserved for highly recalcitrant cases of OLP.

Topical tacrolimus can be used $(43,44)$ two times/day (ointment of Protopic 0.1\%) and seems to have efficiency in reducing symptoms as well as healing lesions of OLP. It has a greater capacity to penetrate the mucosa than cyclosporine but an immunosuppressive action similar to that of cyclosporine and has been successfully used in recalcitrant OLP cases (45). The minimum dosage of Tacrolimus commensurate with efficacy used for a limited period of time is strongly recommended because of its potential to encourage malignant transformation $(46,47)$.

Pimecrolimus has a greater frequency of side effects in the cyclosporin group (48), but $1 \%$ topical cream of pimecrolimus has been used as treatment for OLP, showing good therapeutical results and has low systemic immunosuppressive potential (49).

Mycophenolate mofetil represents another treatment option for severe cases of OLP, but is quite expensive (50). Low molecular weight heparin (enoxaparin) used in low dose, represents a simple, effective and safe treatment for OLP when injected subcutaneously as it has no adverse effects (51).

Recombinant humanized monoconal antibody therapy (Efalizumab) has shown improvement in OLP symptoms when administered once a week as a subcutaneous injection.

In lack of response, retinoids may be useful (tretinoin, isotretinoin, fenretinide), dapsone or hyaluronic acid. Systemic retinoids are used in cases of severe LP, but with significant adverse effects (cheilitis, increase of serologic liver enzymes and triglyceride levels, teratogenicity) (31).

When steroids are contraindicated, an effective drug in erosive OLP is Dapsone, an steroid-sparing agent with minimal adverse effects (usual adult dose is $100 \mathrm{mg}$ per day for 3 months) (52).

Hyaluronic acid in topical administration may have an important role in the treatment of painful erosive oral lesions (46).

There are also some non-pharmacological therapeutic modalities: PUVA therapy, photodynamic therapy (PDT) or laser therapy.

PUVA therapy is a photochemotherapy with 8-methoxypsoralen and long wave ultraviolet light (PUVA). The therapeutic protocol includes oral administration of Methoxypsoralen, followed by $2 \mathrm{~h}$ of UV intraoral irradiation on the affected areas. This protocol has shown encouraging results in the treatment of severe cases of OLP (53).

Photodynamic therapy uses a photosensitizing compound (methylene blue), activated by the laser light at a specific 
wavelength, in order to destroy the targeted cell using strong oxidizers, which cause cellular damage, membrane lysis and protein inactivation; it has been succesfully used to alleviate symptoms of OLP in adult patients (54).

Laser therapy seems to be more effective in treatment of painful erosive OLP, compared with topical super-potent corticosteroids. Their effect is the destruction of the superficial epithelium (containing the target keratinocytes by protein denaturation); in addition, the diode laser also destroys the underlying connective tissue with the inflammatory component along the epithelium (55-57).

For associated extra-oral lesions oral pathologist and dentist will liaise with dermatologist or other specialists, as appropriate.

Review intervals. At present there is no consensus to the optimum review interval (58). General recommendation: Annual review in mild forms, at 6 months in severe forms, and 3-monthly if biopsy shows dysplastic changes.

Patients must be informed about the clinical signs that they should pay attention to, and instructed to use the so-called open appointments whenever noting any changes in clinical features of lesions and/or symptoms.

\section{Conclusions}

OLP is one of the most frequently encountered mucosal pathology by dental practitioners and oral pathologist. It is of great importance to make an accurate diagnosis of the lesions and to establish a proper treatment at the earliest. No therapy currently available for OLP is completely curative; all current therapies have local and systemic side effects and lesions can reappear after treatment is stopped.

The aims of treatment are to alleviate painful symptoms, to heal the ulcerative and/or atrophic lesions, to reduce the risk of malign transformation and to prolong the symptom-free intervals.

Generally, these objectives can be achieved through topical application of corticosteroids, with or without the combination of other immunomodulators. In some case the condition requires systemic therapy. Laser therapy and other recent modalities have shown encouraging results and represent an option as the final remedy. The healing of mucosal erythema and ulceration, with residual asymptomatic reticular or papular lesions may be considered an endpoint of current OLP therapy.

\section{Acknowledgements}

Not applicable.

\section{Funding}

No funding was received.

\section{Availability of data and materials}

The datasets used and/or analyzed during the current study are available from the corresponding author on reasonable request.

\section{Authors' contributions}

DR, RC, AMC, AP and AC contributed to the acquisition of the data, manuscript drafting and critical revision of the manuscript for important intellectual content. All authors read and approved the final manuscript.

\section{Ethics approval and consent to participate}

Not applicable.

\section{Patient consent for publication}

Not applicable.

\section{Competing interests}

The authors declare that they have no competing interests.

\section{References}

1. Eisen D: The clinical features, malignant potential, and systemic associations of oral lichen planus: A study of 723 patients. J Am Acad Dermatol 46: 207-214, 2002.

2. Sugerman PB, Savage NW, Walsh LJ, Zhao ZZ, Zhou XJ, Khan A, Seymour GJ and Bigby M: The pathogenesis of oral lichen planus. Crit Rev Oral Biol Med 13: 350-365, 2002.

3. Ikeda N, Ishii T, Iida S and Kawai T: Epidemiological study of oral leukoplakia based on mass screening for oral mucosal diseases in a selected Japanese population. Community Dent Oral Epidemiol 19: 160-163, 1991.

4. Montebugnoli L, Venturi M, Gissi DB and Cervellati F: Clinical and histologic healing of lichenoid oral lesions following amalgam removal: A prospective study. Oral Surg Oral Med Oral Pathol Oral Radiol 113: 766-772, 2012.

5. Powell FC, Rogers RS III and Dickson ER: Primary biliary cirrhosis and lichen planus. J Am Acad Dermatol 9: 540-545, 1983.

6. Cheonga B, Jones DB, Monkb BE, Pembroke AC, Graham-Brown RAC and Sarkany I: Skin problems in chronic active hepatitis. Lancet 318: 1045-1046, 1981.

7. Payeras MR, Cherubini K, Figueiredo MA and Salum FG: Oral lichen planus: Focus on etiopathogenesis. Arch Oral Biol 58: 1057-1069, 2013.

8. Eversole LR: Immunopathogenesis of oral lichen planus and recurrent aphthous stomatitis. Semin Cutan Med Surg 16: 284-294, 1997.

9. Brănişteanu DE, Brănişteanu DC, Stoleriu G, Ferariu D, Voicu CM, Stoica LE, Căruntu C, Boda D, Filip-Ciubotaru FM, Dimitriu A and Radu CD: Histopathological and clinical traps in lichen sclerosus: A case report. Rom J Morphol Embryol 57 (Suppl 2): S817-S823, 2016.

10. Zhou XJ, Sugarman PB, Savage NW, Walsh LJ and Seymour GJ: Intra-epithelial $\mathrm{CD} 8^{+} \mathrm{T}$ cells and basement membrane disruption in oral lichen planus. J Oral Pathol Med 31: 23-27, 2002.

11. Sugerman PB, Satterwhite K and Bigby M: Autocytotoxic T-cell clones in lichen planus. Br J Dermatol 142: 449-456, 2000.

12. Srinivas K, Aravinda K, Ratnakar P, Nigam N and Gupta S: Oral lichen planus - review on etiopathogenesis. Natl J Maxillofac Surg 2: 15-16, 2011.

13. Calenic B, Greabu M, Caruntu C, Nicolescu MI, Moraru L, Surdu-Bob CC, Badulescu M, Anghel A, Logofatu C and Boda D: Oral keratinocyte stem cells behavior on diamond like carbon films. Rom Biotechnol Lett 21: 11914-11922, 2016.

14. Canto AM, Müller H, Freitas RR and Santos PS: Oral lichen planus (OLP): Clinical and complementary diagnosis. An Bras Dermatol 85: 669-675, 2010.

15. Pindborg JJ, Reichart PA, Smith CJ and van der Waal I: Histological Typing of Cancer and Precancer of the Oral Mucosa. 2nd edition. Springer, New York, NY, pp18-23, 1998.

16. Cheng YS, Gould A, Kurago Z, Fantasia J and Muller S: Diagnosis of oral lichen planus: A position paper of the American Academy of Oral and Maxillofacial Pathology. Oral Surg Oral Med Oral Pathol Oral Radiol 122: 332-354, 2016. 
17. WHO Collaborating Centre for Oral Precancerous Lesions: Definition on leukoplakia and related lesions: An aid to studies on oral precancer. Oral Surg Oral Med Oral Pathol Oral Radiol Endod 46: 518-539, 1978

18. van der Meij EH and van der Waal I: Lack of clinicopathologic correlation in the diagnosis of oral lichen planus based on the presently available diagnostic criteria and suggestions for modifications. J Oral Pathol Med 32: 507-512, 2003.

19. Kamath VV, Setlur K and Yerlagudda K: Oral lichenoid lesions a review and update. Indian J Dermatol 60: 102, 2015.

20. Ianoși SL, Forsea AM, Lupu M, Ilie MA, Zurac S, Boda D, Ianosi G, Neagoe D, Tutunaru C, Popa CM and Caruntu C: Role of modern imaging techniques for the in vivo diagnosis of lichen planus. Exp Ther Med 17: 1052-1060, 2019.

21. Lupu M, Caruntu A, Caruntu C, Boda D, Moraru L, Voiculescu V and Bastian A: Non-invasive imaging of actinic cheilitis and squamous cell carcinoma of the lip. Mol Clin Oncol 8: 640-646, 2018.

22. Lupu M, Căruntu A, Moraru L, Voiculescu VM, Boda D, Tănase $C$ and Căruntu C: Non-invasive imaging techniques for early diagnosis of radiation-induced squamous cell carcinoma of the lip. Rom J Morphol Embryol 59: 949-953, 2018.

23. Ilie MA, Caruntu C, Lupu M, Lixandru D, Georgescu SR, Bastian A, Constantin C, Neagu M, Zurac SA and Boda D: Current and future applications of confocal laser scanning microscopy imaging in skin oncology. Oncol Lett 17: 4102-4111, 2019.

24. Ilie MA, Caruntu C, Lixandru D, Georgescu SR, Constantin MM, Constantin C, Neagu M, Zurac AS and Boda D: In vivo confocal laser scanning microscopy imaging of skin inflammation: Clinical applications and research directions. Exp Ther Med 17: 1004-1011, 2019

25. Lamey PJ, McCartan BE, MacDonald DG and MacKie RM: Basal cell cytoplasmic autoantibodies in oral lichenoid reactions. Oral Surg Oral Med Oral Pathol Oral Radiol Endod 79: 44-49, 1995.

26. Potts AJ, Hamburger J and Scully C: The medication of patients with oral lichen planus and the association of nonsteroidal anti-inflammatory drugs with erosive lesions. Oral Surg Oral Med Oral Pathol 64: 541-543, 1987.

27. Schlosser BJ: Lichen planus and lichenoid reactions of the oral mucosa. Dermatol Ther 23: 251-267, 2010.

28. Neville BW, Damm DD, Allen CM and Angela CC: Oral and Maxillofacial Pathology. 4th edition. Elsevier, Philadelphia, PA, pp675-692, 2016.

29. Rotim Z, Bolanca Z, Rogulj AA, Andabak M, Boras VV and Vrdoljak DV: Oral lichen planus and oral lichenoid reaction - an update. Acta Clin Croat 54: 516-520, 2015.

30. Ostman PO, Anneroth G and Skoglund A: Amalgam-associated oral lichenoid reactions. Clinical and histologic changes after removal of amalgam fillings. Oral Surg Oral Med Oral Pathol Oral Radiol Endod 81: 459-465, 1996.

31. Al-Hashimi I, Schifter M, Lockhart PB, Wray D, Brennan M, Migliorati CA, Axéll T, Bruce AJ, Carpenter W, Eisenberg E, et al: Oral lichen planus and oral lichenoid lesions: Diagnostic and therapeutic considerations. Oral Surg Oral Med Oral Pathol Oral Radiol Endod 103 (Suppl): S25.e1-e12, 2007.

32. Lodi G, Scully C, Carrozzo M, Griffiths M, Sugerman PB and Hongprasom K: Current controversies in oral lichen planus: Report of an international consensus meeting. Part 2. Clinical management and malignant transformation. Oral Surg Oral Med Oral Pathol Oral Radiol Endod 100: 164-178, 2005.

33. Tyldesley WR and Harding SM: Betamethasone valerate aerosol in the treatment of oral lichen planus. Br J Dermatol 96: 659-662, 1977.

34. Gonzalez-Moles MA, Morales P, Rodriguez-Archilla A, Isa-bel IR and Gonzalez-Moles S: Treatment of severe chronic oral erosive lesions with clobetasol propionate in aqueous solution. Oral Surg Oral Med Oral Pathol Oral Radiol Endod 93: 264-270, 2002 .

35. Hegarty AM, Hodgson TA, Lewsey JD and Porter SR: Fluticasone propionate spray and betamethasone sodium phosphate mouth rinse: A randomized crossover study for the treatment of symptomatic oral lichen planus. J Am Acad Dermatol 47: 271-279, 2002

36. Lo Muzio L, della Valle A, Mignogna MD, Pannone G, Bucci P, Bucci E and Sciubba J: The treatment of oral aphthous ulceration or erosive lichen planus with topical clobetasol propionate in three preparations: A clinical and pilot study on 54 patients. J Oral Pathol Med 30: 611-617, 2001.
37. Aleinikov A, Jordan RC and Main JH: Topical steroid therapy in oral lichen planus: Review of a novel delivery method in 24 patients. J Can Dent Assoc 62: 324-327, 1996.

38. Gonzalez-Moles MA, Ruiz-Avila I, Rodriguez-Archilla A, Morales-Garcia P, Mesa-Aguado F, Bascones-Martinez A and Bravo M: Treatment of severe erosive gingival lesions by topical application of clobetasol propionate in custom trays. Oral Surg Oral Med Oral Pathol Oral Radiol Endod 95: 688-692, 2003.

39. Carbone M, Goss E, Carrozzo M, Castellano S, Conrotto D, Broccoletti R and Gandolfo S: Systemic and topical corticosteroid treatment of oral lichen planus: A comparative study with long-term follow-up. J Oral Pathol Med 32: 323-329, 2003.

40. Thongprasom K, Luangjarmekorn L, Sererat T and Taweesap W: Relative efficacy of fluocinolone acetonide compared with triamcinolone acetonide in treatment of oral lichen planus. J Oral Pathol Med 21: 456-458, 1992.

41. Vincent SD: Diagnosing and managing oral lichen planus. J Am Dent Assoc 122: 93-44,96, 1991.

42. Kuo RC, Lin HP, Sun A and Wang YP: Prompt healing of erosive oral lichen planus lesion after combined corticosteroid treatment with locally injected triamcinolone acetonide plus oral prednisolone. J Formos Med Assoc 112: 216-220, 2013.

43. Thompson MA, Hamburger J, Stewart DG and Lewis HM: Treatment of erosive oral lichen planus with topical tacrolimus. J Dermatolog Treat 15: 308-314, 2004.

44. Byrd JA, Davis MD, Bruce AJ, Drage LA and Rogers RS III: Response of oral lichen planus to topical tacrolimus in 37 patients. Arch Dermatol 140: 1508-1512, 2004.

45. Rozycki TW, Rogers RS III, Pittelkow MR, McEvoy MT, el-Azhary RA, Bruce AJ, Fiore JP and Davis MD: Topical tacrolimus in the treatment of symptomatic oral lichen planus: A series of 13 patients. J Am Acad Dermatol 46: 27-34, 2002

46. Eisen D, Carrozzo M, Bagan Sebastian JV and Thongprasom K: Oral lichen planus: Clinical features and management. Oral Dis 11: 338-349, 2005.

47. Lopez-Jornet P, Camacho-Alonso F and Salazar-Sanchez N: Topical tacrolimus and pimecrolimus in the treatment of oral lichen planus: An update. J Oral Pathol Med 39: 201-205, 2010.

48. Thongprasom K, Chaimusig M, Korkij W, Sererat T, Luangjarmekorn L and Rojwattanasirive S: A randomized-controlled trial to compare topical cyclosporin with triamcinolone acetonide for the treatment of oral lichen planus. J Oral Pathol Med 36: 142-146, 2007.

49. Gupta AK and Chow M: Pimecrolimus: A review. J Eur Acad Dermatol Venereol 17: 493-503, 2013.

50. Liu V and Mackool BT: Mycophenolate in dermatology. J Dermatolog Treat 14: 203-211, 2003

51. Hodak E, Yosipovitch G, David M, Ingber A, Chorev L, Lider O, Cahalon L and Cohen IR: Low-dose low-molecular-weight heparin (enoxaparin) is beneficial in lichen planus: A preliminary report. J Am Acad Dermatol 38: 564-568, 1998.

52. Raj AC, Sreelatha KT and Balan A: Dapsone in the treatment of resistant oral erosive lichen planus: A clinical study. J Indian Aca Oral Med Radiol 24: 20-23, 2012.

53. Casale M, Moffa A, Vella P, Rinaldi V, Lopez MA, Grimaldi V and Salvinelli F: Systematic review: The efficacy of topical hyaluronic acid on oral ulcers. J Biol Regul Homeost Agents 31 (Suppl 2): S63-S69, 2017.

54. Akram Z, Javed F, Hosein M, Al-Qahtani MA, Alshehri F, Alzahrani AI and Vohra F: Photodynamic therapy in the treatment of symptomatic oral lichen planus: A systematic review. Photodermatol Photoimmunol Photomed 4: 167-174, 2018.

55. van der Hem PS, Egges M, van der Wal JE and Roodenburg JL: $\mathrm{CO}_{2}$ laser evaporation of oral lichen planus. Int J Oral Maxillofac Surg 37: 630-633, 2008.

56. Cafaro A, Albanese G, Arduino PG, Mario C, Massolini G, Mozzati M and Broccoletti R: Effect of low-level laser irradiation on unresponsive oral lichen planus: Early preliminary results in 13 patients. Photomed Laser Surg 28 (Suppl 2): S99-S103, 2010.

57. Derikvand N, Ghasemi SS, Moharami M, Shafiei E and Chiniforush N: Management of oral lichen planus by $980 \mathrm{~nm}$ diode laser. J Lasers Med Sci 8: 150-154, 2017.

58. Mattsson U, Jontell M and Holmstrup P: Oral lichen planus and malignant transformation: Is a recall of patients justified? Crit Rev Oral Biol Med 13: 390-396, 2002.

This work is licensed under a Creative Commons Attribution-NonCommercial-NoDerivatives 4.0 International (CC BY-NC-ND 4.0) License. 